\title{
A RARE CASE OF LUMBOCOSTOVERTEBRAL SYNDROME WITH SPINAL DYSRAPHISM AND TETHERED CORD
}

\author{
Anjana Trivedi ${ }^{1}$, Maulik Jethva ${ }^{2}$, Pinkal Patel ${ }^{3}$, Nishita Chotai ${ }^{4}$, Jagruti Kalola ${ }^{5}$
}

\section{HOW TO CITE THIS ARTICLE:}

Anjana Trivedi, Maulik Jethva, Pinkal Patel, Nishita Chotai, Jagruti Kalola. "A Rare Case of Lumbocostovertebral Syndrome with Spinal Dysraphism and Tethered Cord". Journal of Evolution of Medical and Dental Sciences 2014; Vol. 3, Issue 17, April 28; Page: 4698-4701, DOI: 10.14260/jemds/2014/2498

ABSTRACT: Lumbocostovertebral syndrome includes abnormalities of the vertebral bodies, ribs and trunk musculature; it is very rare and less than 30 cases have been reported. We have been reported a case of 7 month old female child with absent ribs, bifid ribs, hemivertebrae \& butterfly vertebrae, scoliosis of vertebral column with spina bifida, left lower chest-upper abdominal bulge and tethered cord (features of Lumbocostovertebral syndrome). Embryology and management of the case is discussed.

KEYWORDS: Spinal dysraphism, Tethered cord, Hemivertebrae, Butterfly vertebrae, Spina bifida, Lower chest-upper abdominal bulge, Lumbo-costo-vertebral syndrome.

INTRODUCTION: Lumbo-costo-vertebral syndrome is a rare disorder in children. Less than 30 cases have been reported in the literature so far. It includes vertebral anomalies, congenital absence of ribs, anterior myelomeningocele and hypoplasia of the anterior abdominal wall presenting as congenital lumbar hernia. ${ }^{1-4}$ Other association of the syndrome may be tethered cord \& spinal canal lipoma.

CASE REPORT: A 7-month-old female baby presented with history of swelling in the left lower chest \& upper abdomen. On examination, she was found to have a left lower chest-upper abdominal bulge which is expansile on cough impulse. There was thoracic scoliosis with convexity towards right side. The neurological examination of the lower limbs was normal. Anal tone was normal and superficial anal reflex was elicitable. Directly CT scan of chest \& abdomen was prescribed to the child.

On CT scan images, there was D7 \& D8 hemivertebrae and D9 butterfly vertebrae with absent left $7^{\text {th }}$ to $9^{\text {th }}$ ribs and bifid $6^{\text {th }} \& 10$ th ribs. Low lying tethered cord is noted. USG abdomen also done by us; which showed large anterior abdominal wall muscular defect at left lower chest-upper abdominal regions with protrusion of abdominal contents through the defect on coughing impulse. Left hemidiaphragm is noted superiorly than right side with decreased left sided thoracic cage volume.

DISCUSSION: Lumbo-costo-vertebral syndrome includes hemi-vertebra, congenital absence of ribs, anterior myelomeningocele and abdominal wall muscular hypoplasia. These defects could probably due to a single somatic defect occurring during 3-5 weeks of gestational age, which results in malformation of the vertebral bodies, ribs and abdominal musculature. ${ }^{3}$ During the 3-5 weeks of gestational age neurulation occurs during which formation of the neural groove, closure of the anterior (25 days) and posterior (27 to 28 days) neuropores, appearance of the ventral horn cells, formation of anterior and posterior roots and disjunction of the neuroectoderm from the surface ectoderm takes place. 5 Any disturbance during this stage, probably anoxia as demonstrated in animal studies will result in vertebral, costal and abdominal defects. So the defects of the lumbo-costo-vertebral 
syndrome could be associated with the spinal cord malformations. In our case the patient had absent \& bifid ribs, hemi \& butterfly vertebrae, scoliosis of vertebral column \& spina bifida, left lumbar hernia and tethered cord which is a disorder of primary neurulation.

A lumbar hernia is a parietal wall defect that may occur anywhere in the lumbar region between the $12^{\text {th }}$ rib and the iliac crest. Congenital lumbar hernia is rare. It can occur in the superior (Grynfelt Lesshaft's) or the inferior lumbar (Pet- it's) triangle.7-8 Previously published articles suggest an association between the lumbar hernias and lumbo-costo-vertebral syndrome defects. ${ }^{3,4,9}$ Other abnormalities associated with congenital lumbar hernia, reported so far include congenital sciatic hernia, absent tibia, posterior myelomeningocele, focal nodular hyperplasia of the liver \& absent kidney. ${ }^{10-12}$

Our case describes such a rare combination of anomalies. Un tethering of the cord was done to prevent neurological complications that could arise. Now she is on regular follow up to monitor her neurological status, lumbar hernia and scoliosis. This case highlights the fact that it is vital to investigate these patients with X-ray/ CT scan of abdomen \& chest, ultrasound of abdomen and magnetic resonance imaging of the spine to rule out the associated abnormalities and the need for regular multidisciplinary follow up.

\section{REFERENCES:}

1. Lee CM jr. Mattheis H. Congenital lumbar hernia. Arch Dis child 1957:32:4-7.

2. Talukadar B C. Congenital lumbar hernia. J Pediatr Surg 1974:9:419-20.

3. Tolonkian RJ. The lumbo-costo-vertebral syndrome; a single somatic defect. Surgery 1972:71:174-81.

4. Bernay F, Gidnex, Gurses N. Superior lumbar hernia associated with the lumbo-costo-vertebral syndrome. Pediatr Surg Int 1990:5:469-70.

5. Pang D. Spinal cord lipomas in disorders of pediatric spine, (ed) Raven press, Ltd: New York; 1995. P. 178-9.

6. Ingalls TH, Curley FJ, Prendle RA. Experimental production of congenital anomalies: Timing and degree of anoxia as a factor causing fetal deaths and congenital anomalies in the mouse. $\mathrm{N}$ Engl J Med 1952; 247: 758.

7. Gyrnfelt J. Quelques most sur la hernie lombaire. Montpellier Med 1866; 16: 329.

8. Lesshaft P. Die Lumbalfefend in Anatomische ehirugischer Hinsieht. Arch Ant Physiol. Wissensch Med 1870; 37: 264.

9. Haneock Bj, Wiseman NE. Incarcerated congenital lumbar hernia associated with the lumbocosto-vertebral syndrome. J Pediatr Surg 1988; 23: 782-3.

10. Loftus BG, O'Carroll T. Lumbar herniation and tibial absence in infants of diabetic mother. Diabet Med 1985; 2: 283-5.

11. Lowell DG, Guzetta PC. Lumbar hernia in a case of posterior meningomyelocele. J Pediatr Surg 1986; 21: 913-4.

12. Al-salem Ah, Abu-Arair H, Qaissaruddin S. Focal nodular hyperplasia of the liver with lumbocostovertebral syndrome. J Pedatr Surg 1996; 31: 1282-4. 


\section{CASE REPORT}

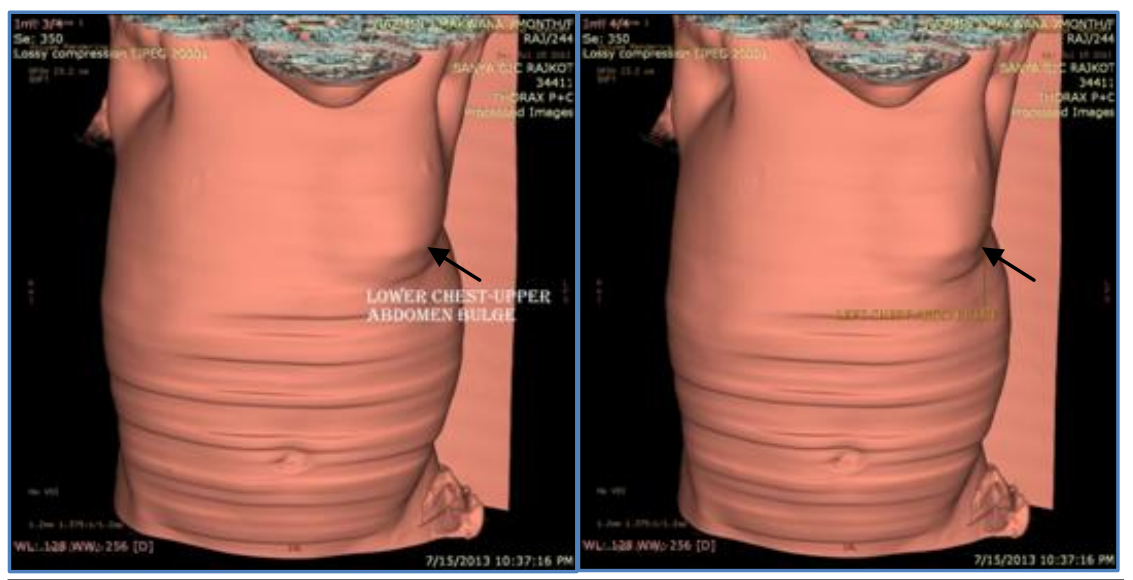

SSD Image shows left lower chest \& upper abdomen bulge

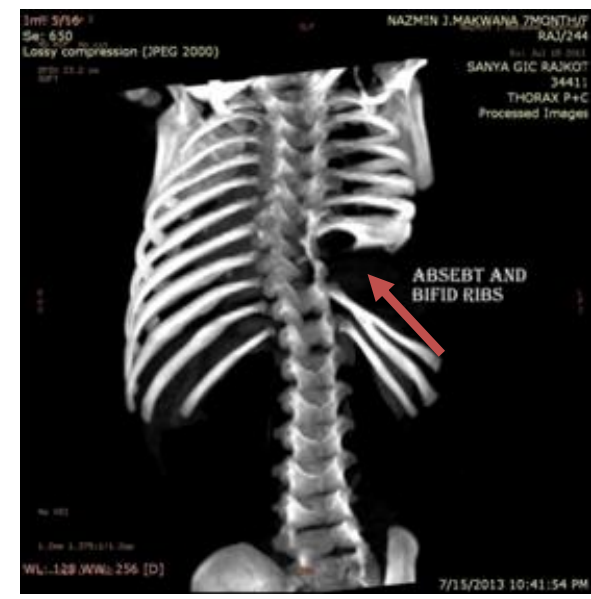

Bone 3D Image shows left side absent and bifid ribs

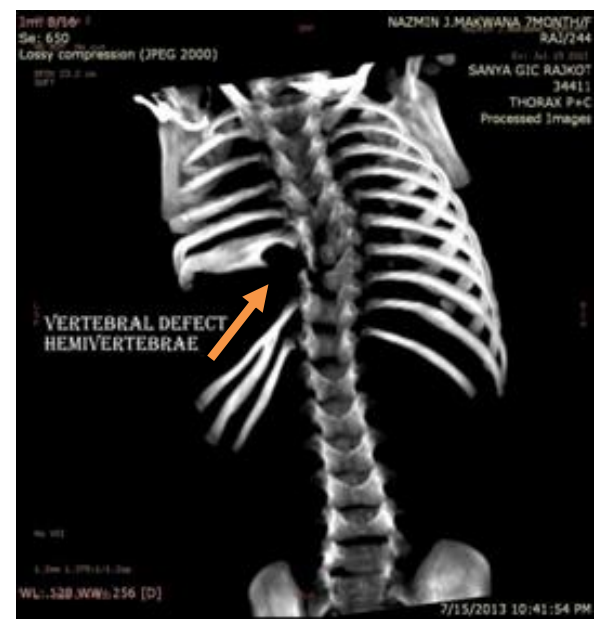

Bone 3D Image shows left side vertebral defect, hemivertebrae 


\section{CASE REPORT}

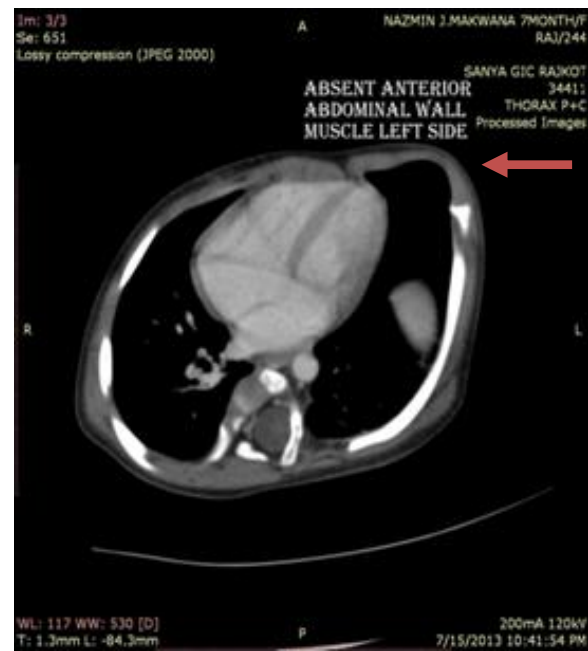

Axial Image shows absent anterior abdominal wall muscle left side

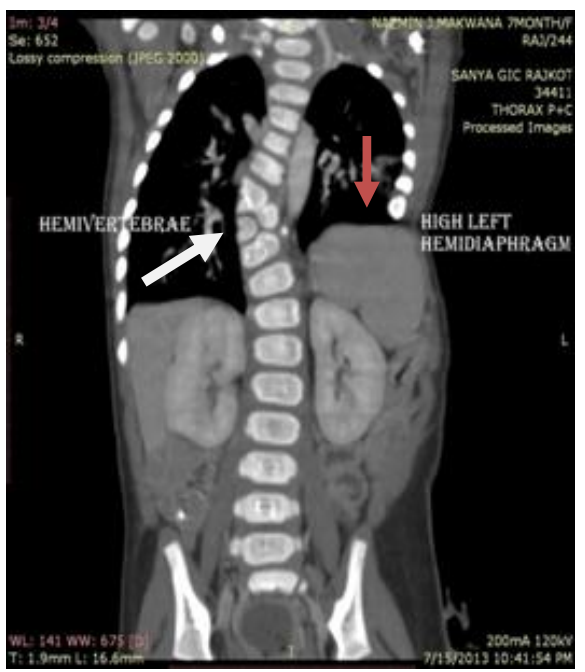

Sagittal Image shows hemivertebrae \& high left hemidiaphragm

\section{AUTHORS:}

1. Anjana Trivedi

2. Maulik Jethva

3. Pinkal Patel

4. Nishita Chotai

5. Jagruti Kalola

\section{PARTICULARS OF CONTRIBUTORS:}

1. Professor and HOD, Department of Radiology, PDU Civil Hospital, Rajkot, Gujarat.

2. Assistant Professor, Department of Radiology, PDU Civil Hospital, Rajkot, Gujarat.

3. Resident Doctor, Department of Radiology, PDU Civil Hospital, Rajkot, Gujarat.

4. Consultant Radiologist, Department of Radiology, Sahyog Imaging Center, PDU Civil Hospital, Rajkot, Gujarat.
5. Associate Professor, Department of Radiology, PDU Civil Hospital, Rajkot, Gujarat.

\section{NAME ADDRESS EMAIL ID OF THE CORRESPONDING AUTHOR:}

Dr. Anjana Trivedi,

Professor and HOD,

Department of Radiology,

PDU Civil Hospital,

Rajkot, Gujarat.

E-mail: dranjanatrivedi@yahoo.co.in

Date of Submission: 09/03/2014.

Date of Peer Review: 10/03/2014.

Date of Acceptance: 28/03/2014.

Date of Publishing: 28/04/2014. 